\title{
¿Tiene China una política exterior?
}

JonN GITtNGs fuc investigador del Rojal Institute of International Affairs en Londres. Es ahora profeser-investigador de asunios de Asia en el Instituto de Estudios Internacionales de la Liniversidad de Chile. Es el autor de The Role of the Chinese Army (Oxford University Press, 196i). Este artículo está basado sobre una conferencia dictada en el Salón de Honor de la Universidad de Chile, el 24 de noviembre de 1966.

Al plantear este tema en forma interrogativa queremos indicar desde un comienzo el grado de incertidumbre y' de ignorancia en que nos encontramos frente a todo lo que se refiere a la política exterior china. Como causa de esto debemos señalar tres importantes limitaciones.

La primera de esas limitaciones es, sencillamente, nuestra falta de conocimientos. Sabemos menos sobre el funcionamiento de la política exterior en China - cómo se formula, cómo se toman las decisiones- que sobre casî cualquier otro aspecto de su política interna. Podríamos enumerar 6 partidos y 17 organizaciones gubernamentales, fuera de unas 20 organizaciones semioficiales, que de algún modo están relacionadas con la política externa. Sin embargo, tanto los lazos de unión entre estas entidades, como su precisa relación de mando nos son casi totalmente desconocidos.

Tampoco estamos mejor informados respecto al pensamiento teórico y analítico que sine de base a la politica exterior china, excepto en los planteamientos más generales. No se publica en China nada de calidad similar a Intcrnalional Affairs de la Unión Soviética, donde todo lo arriba indicado se expone detalladamente. Los chinos publican muchísimo más, por ejemplo, sobre la teoria y práctica económica que sobre la teoria de las relaciones internacionales y la práctica de la política externa.

Consiste la segunda limitición en la tendencia de los observadores extranjeros a dar una importancia muchísimo mayor a la politica exterior china que los propios interesados. El Occidente por lo general se preocupa y opina sobre la actuación de la China en el exterior y le presta escasa atención a los desarrallos internos, salvo en momentos de gran tensión y dramatismo como el Gran Salto Adelante o la Revolución Cultural actual. Sc puede argüir que la jefatura china, muj por el contrario, sc preocupa mucho más de la politica interna que de la cxterma y claramenc prefiere dedicarle una inajor solicitudy rellexión a la primera. 


\section{John Cittings / ¿Tiene Chins una potitien exterior?}

Por último, tambien se tiende a considerar a la politica externa de China como un todo completamente articulado $\mathrm{y}$ formulado en todos sus posibles alcances. Por estos motivos el fin de nuestro análisis debe ceñirse a indicar cuál seria la línea politica seguida según la circunstancia dada. Previamente debemos reconocer que China en muchos puntos de su politica cxterna no sigue fórmula alguna y que por lo denás, tal conducta no seria exclusiva de dicho pais.

Podemos ya indicar que la politica extcrior china es en realidad muchisimo más incipiente y fragmentaria que se podría pensar. Este fenómeno se explica no sólo por las actitudes mentales e ideologia de la jefatura china, sino también por el contexto internacional en que China se ha encontrado desde la.victotia comunista de 1949. En la medida que la política externa se hacia más coherente, paulatinamente se tornaba más negativa, a consecuencia de muchos años de frustración y aisłamiento. En los años 1965-66 se ha mostrado marcadamente introspectiva y en muchos campos pierde ya totalmente su primitiva cualidad de politica para el exterior.

La política-externa china se puede dividir en tres fases distintas. Sabemos que cortar en períodos cualquier flujo continuo de sucesos inevitablemente lleva a una hipersimplificación, por lo que estas tres fases no deben ser in. terpretadas literalmente, sino como una función ilustrativa.

Las características negativas de esta politica son ya notorias durante la primera etapa, iniciada aproximadamente desde la victoria comunista de 1949 hasta el término de la guerra de Corea. Brillan nuevamente durante la tercera - actual etapa, principiada con el Gran Salto Adelante, y adquieren su má: ximo vigor durante los dos últimos años. Sin embargo, la segunda etapa intermedia se caracterizó como un período de flexibilidad y experimentación; durante el cual la jefatura del país comenzó a ejercer una diplomacia activa y a buscar soluciones realistas a los problemas que debia afrontar. Fueron muchos los motivos que produjeron la pérdida de esta flexibilidad y este será el objeto principal de nuestro estudio.

\section{Primera etapa de la Polf́tica Extekjor de China}

La primera decisión sobre politica cxterior tomada por el nucvo gobierno comunista de China al asumir el poder en 19.19 fuc la de "inclinarse a un lado", uniendo su suerte decididamente a la de la Unión Soviética. Esta decisión fue forrualizada por medio del Tratado Chino-soviético de Amistad, Alianza y Ayuda Mutuas, firmado el 23 de febrero de 1950. Este paso, celebrado como valiente y dramático, fue aplaudido por el mundo comunista y en cambio deplorado por el mundo occidental como algo perverso e innecesario. Desde ambos puntos de vista parecia demostrar que el nuevo lide: rato chino poseia una notable labilidad para actuar positiva y teminantemente en el compo cxterno. 
Sin cmbargo, una miracla retrospectiva plantea la interrogante sobre cuál otra alternativa les cra posible. En priner lugar, la situación mundial en el año 1919 les impedia ser sutiles o ambiguos en la politica externa. Esc misuo año se formó la ordx, en los nomentos en que las gelidas llamas de la guerra fria eran más altas. El nuevo gobierno de Pekín necesitaba antes que nada un "aliado seguro", -que uno de los dos grandes poderes protegiese a la China del otro y la permitiera vivir un periodo de calma para rehacer su cconomía destruida y retornar a una paz ya casi olvidada.

La elección de la Unión Sovićtica como un "aliado seguro" era obvia y no fue motivada solamente por las tendencias ideológicas de los comunistas. Estados Unidos habia apoyado al Kuomintang durante todo el transcurso de la guerra civil, aunque el respaldo fucse dado a disgusto y sin entusiasmo. Ademís, descle un comienzo Estados Unidos demostró su hostilidad hacia el nuevo gobierno de Mao Tse-tung. Algunos historiadores han argumentado que durante los primeros meses en ejercicio del nuevo gobierno comunista Estados Unidos evitó toda acción que pudiese llevar hacia una disminución eventual de las relaciones con Pekín. De acuerdo con esta in. terpretación, fueron los comunistas quienes, empujados por su tozudo e implacable antinorteamericanismo, irrevocablemente aumentaron la brecha en. tre Pekin y Washington.

Esta teoría no concuerda con los hechos. Ya en abril de 1949, cinco meses antes cle que se estableciese la República Popular, Estados Unidos rechazó una gestión de los comunistas chinos para discutir su eventual reconocimiento. De ahí en adelante Estados Unidos siempre rehusó todas las proposiciones sinilares y aconsejó a sus aliados que dilatasen el reconocimiento del nuevo gobierno para un futuro indefinido. Discursos públicos del Secretario de Estado Dean Acheson dejaban en claro que Estados Unidos, en ese momento, no tenía la menor intención de intervenir en China. Pero también dejaba en claro su opinión de que el gobierno chino era una "herramienta del imperialismo soviético" y que esperaba verlo derrocado por la oposición interna. Todo esto no puede considerarse como una actitud de "no tocar".

Fuera de las realidades externas de la guerra fria, hay otros dos factores que influyeron en el entusiasta acercamiento de China a la Unión Soviética. Primeramente, los comunistas chinos carecian de toda experiencia en la conducción de politica cxterna y ademís el factor tiempo les era muy importante.

La victoria llegó para los comunistas chinos mucho antes de lo que cllos, o cualquier otra persona, esperaban. Se debian tosar decisiones rapidas sobre toda clase de politica, induyendo la externa. Los vencedores no poscian cxperiencia alguna en el campo de las relaciones semidiplomíticas con paises simpatizames durante su revolución; lo que no stecede actualmente en el Frente de Liberación ?Tacional de Vietnam o como fue el caso 


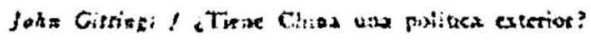

del rzx en Argelia. Durante he guerra civil se vieron aislaclos no vilu lisica sino también politicanente del rosto del mundo. Incluso la Unión Sor ictica les habia aconsejado en 1916 que evitasen una gucrra civil $y$ cuando cste conscjo fue ignorado, redujeron mucho su ayuda. Por este motivo, cra de esperar que llegado cl.moracnto en que una decisión ripida fuese necesa. ria, los comunistas chinos recurririan nuevamente a las posiciones ideologicas familiares $y$ se inclinarian hacia el lado soviético. Por muy mal que tos hubiese tratado Sialin en el pasado, no cabia otra alternativa por el momento.

Esta primera etapa de la politica exterior china, descle 19.19 hasta el fin de la guerra de Corea, tiene por lo tanto dos características primordiales: inexperiencia e inflexibilidad ideológica. El grado alcanzado por esta inflexibilidad se refleja en la actitud china hacia las nuevas naciones que emergian, tales como Indonesia, India y Birmania, a las que consideraba como lacayos burgueses del imperialismo. Esta opinión simplista respecto a Sukarno, Nehru y U Nu, chocaba con la actitud muchisimọ más acomodaticia de los soviéticos y fue modificado - posiblemente bajo presión de éstosen 1951. De un modo igualmente doginático, el liclerato chino proclamaba que el "camino de Mao Tse-tung" era el único a tomar en la lucha contra el colonialismo.

La guerra de Corea solamente contribuyó a inhibir el desarrollo de una política externa china independiente, ya que aumentó su dependencia económica y militar de la Uuión Soviética. También la visión retrospectiva nos muestra que la decisión tomada por China de intervenir en la guerra fue mucho más inevitable que lo que se suponía. El prestigio del nuevo gobierno comunista de Pekín se hubiese visto seriamente dañado si éste no hubiese actuado cuando las fuerzas de las Naciones Unidas invadieron Corea del Norte. Si esta invasión hubiese tenido éxito, habría llevado al poder norteamericano hasta las mismas fronteras del noreste chino. Ningún gobierno chino que se respetase podía permitir tal amenaza para su propia seguridad.

\section{SEGUNDA ETAPA DE, LA POLFTICA EXTERIOR DE CHINA}

Sólo al llegar a 1953 China se transformó en un país física y psicológicamente capaz de desarrollar una política exterior independiente. Al fin estaba en paz -por primera vez en 15 años- deste la agresión de Japón en 1937. El término de la guerra de Corea disminuyó la dependencia china de la Unión Sovictica y permitió que se dieran los primeros pasos hacia un planeamiento económico serio - el Primer Plan Quinquenal comenzó en 1953- $y$ creó un clima mís relajado dentro del cual la politica externa podia ser obscr. vada con perspectivas a largo plazo.

En 1953 en adclante, la political exterior china asumió una forma nats 
sofisticada. Sus intenciones eran abiertas y directas: reestablecer a la China en el papel de un gran poder y aumentar su libertad de acción; fortalecer la influencia de China, principalmente en el Tercer Mfundo y especialmente en Asia; y, aunque cvitando más guerras, proteger los intereses y la seguridad de China:

Los métodos utilizados para conscguir estos fines fueron diversos, flexibles e inteligentes. En sus relaciones con el mundo comunista, tuvo buen cuidado de no desafiar la supremacía soyiética directamente. Pero también respaldó la tendencia hacia un policentrismo en Europa Oriental, apoyando a Polonia (aunque no a Hungria) en sus desavenencias con la Unión Soviética en 1956. China también Jogró obtener concesiones directas de los soviéticos: la derolución de Port Arthur y de la línea férrea de Changchun en Manchuria, la entrega de los intereses económicos soviéticos en la provincia de Sinking, así como un nuevo empréstito y varias formas de asistencia técnica. En Asia, China trató, con bastante éxito, de probar a sus vecinos que no tenia designios velados respecto a ellos y que se sentía fuertemente obligada a cumplir con los principios de la coexistencia pacífica. I.a habilidad con que esto fue manejado por Choú En-lai en la Conferencia de Bandung de 1955 es una obra maestra de la diplomacia. China parecía competir abiertamente con la Unión Soviética por la influencia dentro de esta área, -y portaroces chinos alegaban, con bastante justificación, que hablaban por "Ia totalidad de Asia". China también demostró maestría inesperada del oficio diplomático en la Conferencia de Ginebra de 1954 sobre Indochina y Corea. Por lo demás, fue una moción de China la que dio la solución de arreglo que resultó en la división del Vietnam a lo largo del paralelo 17, a pesar de notorio desacuerdo de Vietnam del Norte. Y también sẹ debió a la iniciativa china el que reumiones a nivel de embajador chinonorteamericano comenzaran a efectuarse regularmente. En realidad, la actitud de China hacia Estados Unidos era mucho menos antagónica que la opuesta. China también empezó a diversificar su comercio exterior, extendió su reconocimiento diplomático a una cantidad de paises no-comunistas, y hasta comenzo un sustancial programa de ayuda externa - principalmente a Corea y Vietnam del Norte, pero tambien a cierto número de paises afroasiaticos.

\section{TERCERA FTAPA DE IA POLITIGA EXTERIOR DE CHLNA}

La jelatura china, desde el Cran Salto Adelante, se orientó hacia una polítea extcrior más dura y nás dogmática. Sintomas de este cambio se manifestaban cuando en noviembre de 1957, dirame el desarrollo de la reunión en Moscú de Partilos de Trabajadores y Comunistas, aparecieron las primeras diferencias de opinión respecto a ta estrategia adecuada frente al Oreidente. Este cambio se tgudizo en 1958-1959, años de la crisis de las islas 


\section{John Gittings / ¿Tiene China una politica exterior?}

costaneras, de la revuclia del Tibet y del primer conflicto chino-hindú sobre limites. Fue también en 1958.59 cuando China rechazó proposiciones sovieticas en el sentido de planificación militar conjunta y finalmente decidió seguir por si misma cn la busca de un disuasivo nuclear.

A traves de los años, los rasgos más importantes de esta linea dura de la politica exteric: son claramente visibles. Primero y antes que nada, está la disputa chino-soviélica, durante la cual China, muchas veces antes que Rusia, es quien fucrza el paso y se niega a aceptar cualquier compromiso. En segundo lugar, aunque China ha continuado su línea de conquista de simpatías dentro del Tercer Mundo, sus esfuerzos han sido poco exitosos y ha comenzado* a perder interés en esto. Tercero, el apoyo verbal $y$ aun a veces material hacia los movimientos de liberación nacional ha suplantado el anterior énfasis a la coexistencia pacífica y a la no intervención en asuntos internos de paises con sistemas políticos y sociales diferentes. Cuarto, la. perspectiva de llegar a algún tipo de acomodo con los Estados Unidos, aun: que fuese de: un carácter limitado, ya no se consideraba como una proposi-: ción realista para el momento actual. Esto, a la vez, ha influido sobre la actitud de China hacia las Naciones Unidas; a las que manifiesta creciente escepticismo. Esta orientación hacia una política más rígida no es en módo alguno arbitraria o irracional. Refleja tanto las presiones externas y el cambio que en general ha habido en el molde mundial de asuntos internacionales, como es a su vez una consecuencia natural de la búsqueda china dirigida hacia la obtención de un papel con rango de gran poder.

La disputa chino-soviética no debió sorprender a nadie, salvo a aquellos que aun se suscriben al mito de una conspiración comunista mundial y monolitica. Siempre existió una ambigüedad latente en las relaciones de China con la Unión Soviética. Era esa relación entre una potencia mun. dial establecida y una potencia mundial incipiente, y como tal estaba des. tinada a ser frágill y descquilibrada. Sicmpre hubo un fondo de tensión. entre ambas naciones desde 1949. A mediados de la decada del 50 los motivos originales, económicos y estratégicos, para mantener esta alianza comenzaron a desaparecer. El molde económico soviético habia empiricamente resultado inadecuado para resolver el problema específico chino de un rápido y continuo crecimiento del poder de fuerza humana. A medida que el acuerdo Occidente-Oriente se desarrollaba, China comenzó a dudar, con razón, sobre el valor de contar con la Unión Soviética como aliado militar. El liderato chino podia argïir plausiblemente, que una cventual maduración. hasta ocupar su lugar como gran potencia se veria impedida si continuaba atada infantilmente a Ja Unión Soviética.

Tampoco es un fenómeno aislaclo el rechazo chino de ambos superpoderes. En la atmósfera más relajada oel entendimierito occidental-oriental, muchas naciones del Iercer Mundo ban tratado de sustraerse de esta bipolaridad artificial inducida por los primeros años de aguda guerra fría. Ia diso: 


\section{ESTUDIOS I Y TER X A C I O X A LES}

ciación de China llama más la atcnción simplcmente por ser esta una na. ción mucho más grande y con un inmenso potencial de poderio propio. Para ponernos al dia, habria que agregar que la tendencia hacia el neutralismo del Tercer Mundo durante la decada recién pasada ha sido en gran parte abandonada en los úlumos años. El desencanto de la China con el concepto del neutralismo refleja especialmente este factor.

Tampoco debe sorprendernos la mayor dureza de la línea china hacia Norteamérica. Aquel pafs en ningún momento habia tratado de aprovechar la fase moderada de la política exterior de China a mediados de los años 1950-1960. China continuó siendo rodeadia y amcnazada por los Estados Unidos que continuó respaldando las fuerzas de ocupación militar en Taiwan e incluso inició o fomentó vuelos de espionaje $y^{\prime}$ misiones de comandos dirigidas en contra de China continental. Tampoco fue modificada la oposición norteamericana a la admisión de China dentro de las Naciones Unidas. Si China continúa fuera de esta organización es solamente debido a la fuerte influencia y oposición de Estados Unidos. Norteamérica también continuó con su bloqueo absoluto al comercio exterior chino y trató de coercer a sus aliados en el mismo sentido. Por añadidura, en la medida que los Estados Unidos y la Unión Soviética llegan a cierto acercamiento, China se aisla y se torna cada vez más temerosa de sus intenciones.

Por lo tanto, era natural que se operase un giro en la política moderada de mediados de la década anterior. Sin embargo, todas estas razones no logran justificar totalmente la violencia del cambio, el que ha sido innecesariamente drástico. Para comprender bien este fenómeo, y para encontrar algún sentido dentro del estilo tan idiosincrásico asumido actualmente por la polftica exterior de China, habría que considerar la siempre creciente influencia de la ideologia de Mao. El vigoroso sentimiento nacionalista chino, y su búsqueda de la "autosuficiencia", han dejado su marca tanto en la política externa como en la interna.

Parece ser que la excesiva dependencia en que cayó China respecto a la Unión Soviética - dependencia que entonces fue aceptada e incluso estimulada- actualmente induce a una violenta reacción que no es posible explicar total y únicamente bajo los términos de una polftica nasional. En 1949 Mao Tse-tung había proclamado triunfalmente: "Ahord podemos firmemente estar de pie, los dias en que se nos consideraba inferiores ya pasaron". Pero estas palabras eran sólo parcialmente verdaderas; Ia alianza chinosoviética perpetuo, aunque tal yez en forma más débil, el mismo sentimiento de nacionalismo frustrado que había fermentado en China a lo largo de todo el siglo pasado. $\mathrm{Y}$ ademaj, si es que China habria de ser un gran poder, como era su firme determinación, seria sumamente dificil generar el dinanismo interno necesario a este fin si continuaba cncadenada a uno de los dos superpoderes existentes. Podemos estar seguros que los insultos y desaires, imaginarios o reales, que el partido comunista chino sufrió en manos 


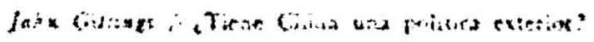

del partido soriético, en aqueilo; dias anteriores a la libersción, nunca habian sido enteramente olsidados. La separación de China de la tinión Sovictica fue hasta cierto punto una manifestacion de un resuagente nacionalismo. Algunos observadores en Chiria informaron que esta cra antes que nada una medida popular, en especial entre aquellos menos seducidos por el gobierno comunista.

La China Imperial ha sido muchas veces descrita como xenofóbica en cuanto a su relación con el mundo externo. Autosuficiente sería un término mejor, ya que en realidad China en aquel entonces era verdaderamente capaz de satisfacer todas sus necesidades sin recurrir mís alli de sus fronteras. Por lo demás, las grandes dimensiones del pais estinulaban un chinocentrismo que era a la vez tanto natural como necesario. El debilitamiento de la dinastia Ch'ing no demostró que una política autosuficiente estuviese errada. Simplemente demostró que tal politica era lábil a la corrosión del imperialismo colonial occidental. China no se desintegró por haber despreciado los regalos de occidente, sino porque estos regalos no eran en absoluto bienvenidos y sin embargo se veia forzada a aceptarlos. China hoy en dia ha vuelto a esta politica de autosuficiencia, y con mayor éxito, ya que ahora es más fuerte para clefenclerse. Esta politica se expresa de muchas maneras - el continuo rechazo a la ayuda externa, la constante proclamación de que el modo de vida chino es único y superior, y un siempre creciente desinterés e impaciencia respecto al mundo exterior.

Otro factor de gran importancia es la personalidad predominante de Mao Tse-tung mismo. No cabe duda de que Mrao en persona ha sido la fuerza motora tras los tres sucesos apocalipticos de la historia china reciente -el Gran Salto Adelante, el Rompimiento chino-soviético y la Revolución Cultural. Con la omnisciencia de la vejez, Mao no teme llegar con estos movimientos a límites que tal vez atemorizarian a sus camaradas más cautelosos. La creciente contradicción no augura en absoluto medias aguas o compromisos. Ganancias a corto plazo tienen importancia minúscula al lado del ideal futuro de una sociedad socialista tan pura como el cristal, aunque ésta demore siglos y sufra innumerables vicisitudes. Como una analogía con el esfuerzo revolucionario de antes 1949, el camino podrá ser largo y dificil, pero la causa justa será la que finalmente triunfe. Se podría describir esta manera de pensar como una doctrina milenarista - pues nada reviste demasiada importancia en el futuro próximo ya que las profecías de Nao estin destinadas a cumplirse en un final lejano. Siguiendo tal doctrina, se pucde China hacer de enemigos impunemente ya que éstos ideológicamente están equirocados y por lo tanto predestinados a una derrota.

Los hechos que más se han destacado dentro de la actitud de China en el campo de las relaciones exteriores, en los iltimos años son: Primero, desencanto respecto a la Unión Sorićtica; segundo, rechazo de toda posibili- 
dad de compromiso con los Estados Unidos en el mómento actual; terecro, un sentido nacionalista a la vez resurgente y en seguida militante; cuarto, un creciente enfasis de la politica de autosuficiencia, y quinto, la preponderante influencia de la doctrina de Mao. Estos factores se han combinado para producir una politica exterior esencialmente pasiva y defensiva, dentro de la cual la acción se posterga en cuanto a lo que es fundamentalmente importante para un futuro indefinido. Esta retimda hacia una actitud pasiva y casi de espera, ha aumentado notablemente durante 1966.

Se puede ilustrar esta tesis con varios ejemplos especificos extraidos de la politica china:

\section{LA RELACIÓN DE ChINA CON EI TERCER MUNDO}

Dentro de todo el campo que abarca la política exterior china, es aquí donde se ha demostracio mayor continuidad y consistencia desde mediados Je la decada pasada y la Conferencia de Bandung de 1955. A medida que China, buscaba establecerse como un posible gran poder, independiente de los dos superpoderes, el apoyo del tercer mundo se tornaba más importante. Además, solamente dentro de este mundo lograria encontrar China la simpatía necesaria, entre paises que tal vez eran más pequeños y menos poderosos, pero que compartian la misma experiencia histórica de subdesarrollo e imperialismo.

El interés chino y su relación con este Tercer Mundo se ha ido incrementando por medio de una serie de ondas geográficas de expansión. La Conferencia de Bandung dio la oportunidad de estrechar los lazos de unión con sus vecinos asiáticos. En 1959, relaciones diplomáticas y de intercambio comercial abarcaban ya una serje de países del Cercano y Mfedio Oriente. Se había intercambiado representantes diplomáticos con Egipto, Siria, Yemen, Ceilán, Iraq, Afganistán, Marruecos y el Sudán. Acuerdos comerciales habian sido formados con la casi totalidad de estos paises. Desde entonces, el interés de China se ha cxtendido aún más, hasta incluir Africa y LatinoAmérica. Esta política fue estimulada por el nacimiento de nuevas naciones independientes en el Africa, por la revolución cubana en Latinoamérica y, ademís, por eliereciente deseo chino de desafiar a la influencia soviética dentro de estas áreas. En 1965, de los 49 paises con los cuales China mantiene relaciones diplomáticas, 13 se encuentran en el continente africano. Dicz de estos hon recibido aiguna ajuda china y la majoria han firmado acuerdos comerciales.

Por razoncs obvias, las relaciones de China a nivel oficial con Latinoamerica son minimas -aparte de Cuba. El intercambio comercial está limitado a solo seis paises y consiste principalmenze en importaciones de trigo argentino. Contactos culfuraies a nivel no-oficial han aumentado a saltos desde 
1959 en adelante. Por ejemplo, en los dos años 1959 y 1960. China envió 24 delegaciones a 15 paises latinoamericanos y dio hospitalidad a más de 200 delegaciones de 21 paises.

Sin cmbargo, a pesar de todas estas actividades, la simpatía que disfrutaba China entre los pafses del Terecr Mundo ha sin duda disminuido durante los dos últi ios años. Ya es lugar común mencionar los errores de la política extcrior china en tal sentido. Aunque a menudo se afirma que es la propia conducta china la responsable de estas pérdidas, las razones que la motivan son en realidad más complejas.

En primer lugar, China es la que más ha sufrido a expensas del desengaño general sobre la viabilidad del neutralismo. Casi es norma general que la primera acción después de un golpe de estado de derecha que se res. pete, ha sido la expulsión de las misiones diplomáticas o comerciales de China. Asi sucedió en Burundi en 1965, en la República de Africa Central y Dahomey en 1966. (A nadie sorprendió la medida tomada por Dahomey, donde el jefe. del golpe, coronel Soglo, era amigo personal de Chiang Kajshek). En Ghana tanto China como Rusia han sufrido igualmente con el derrocamiento de Kwame Nkrumah. En Brasil, en 1964, el nuevo régimen de inmediato ordenó expulsar y aprisionar una Misión Comercial China. Indonesia es otro caso donde China ha sufrido las consecuencias de un golpe de estado de derecha. Muy por el contrario a lo que es opinión popular, China no tuvo papel de significancia alguna en los sucesos del otoño de 1965, los que llevaron a la disolución del Partido Comunista de Indonesia, la ascensión al poder del ejército y la matanza de unas 300.000 personas inocentes dentro de lo que se habia transformado en una guerra racista antichina y una cacería de brujas anticomunistas.

Una razón más fundamental para la declinación de la influencia china en el Tercer Mfundo yace en la propia ambigüedad de la posición de China. Por un lado, China atrae las simpatías por compartir caracteristicas similares - color, subdesarrollo, victima del imperialismo occidental en el pasado-. Por otro lado es un posible superpoder y por lo tanto con otras caracteristicas sumamente distintas. A medida de que China adquiere los atributos de un gran poder, sus actuaciones son causa de sospechas. $\mathrm{Al}$ adquirir el poder nuclear, China ha perdido más aliados que los que ha ganado. Dentro de toda Africa, solamente Guinea y el Congo (Brazzaville) felicitaron a China por su última prucba atómica de octubre de 1966. Rumores temerosos de posibles trastornos chinos $\rightarrow$ a menudo exagerados $\rightarrow$ han comenzado a circular, al mismo tiempo que algunas grotescas teorfas sobre las intenciones de China. Fuc el Presidente Houphouet-Boigny, de la Costa de Marfil, quien declaró que los clinos "andan en busca de espacio, y esa es la razón por la que se sienten atrafdos por el vacio de Alrica".

Además, a pesar de la pretensión China de prestar ayuda cconómica y respaldo politico en gran escala, a menudo se ve imposibilitada para cumplir 
con k prometido. Cin.t cantidad de compromisos de asistencia chinos no han sido cumplidos - con Indoncsia, Birmania, Ccilin y algunos patses de Afri. ca-. Durante dos crisis importantes, Vietnam y la guerra entre India y Pakistán, ha sido Rusia $y$ no China quien ha podido ejercer el importante papel de gran poder moderador. Fsta lección no se pierde ante los ojos de naciones todavia dudosas del Tercer Míndo.

Fiay que reconocer, sin embargo, que la China ha cometido serios errores, que se deben principalmente a juicios precipitados y a una actitud demasiado dogmitica dentro de la politica externa. Aunque la guerra chino-hindú sobre limites de 1962 fue más bien provocada por la India, sin embargo la invasión y subsiguiente negación terminante a aceptar la proposición de arreglo sugerida por los poderes de Colombo, fueron hechos que nacla la favorecieron.

Las tácticas chinas durante las dificiles negociaciones de la desastrosa Conferencia Afro-Asiática - "segunda Bandung"- de 1965 fueron sumamente torpes y mal aconsejadas. Llegó el momento en que China se encontró en la absurda posición de primero haber exigido que la conferencia se efectuase, yendo así contra el deseo de muchos, y después pedir precisamente lo contrario cuando ya varios paises deseaban su realización. En tal caso, su mejor recurso hubiese siclo mantenerse silenciosa durante todo el debate. La actuación de China durante el conflicto Indo-Pakistano, del nismo año, también brilló por su falta de sutileza y seguramente fue más bien una incomodidad que una ayuda para Pakistán. Finalmente, ese afán de China de arrastrar consigo a todas partes la disputa chino-soviética, sea esta una reunión internacional de periodistas o tal vez un congreso de científicos veterinarios, muy comprensiblemente ha causado malestar entre los delegados afro-asiáticos, quienes naturalmente prefieren no perder tiempo durante tales reuniones.

\section{Apoyo GHiNo A MLOVMmENTOS REVOLUGIONARIOS}

El aspecto de la politica exterior de China que tal vez alarma y preocupa más que cualquier otro, es el decidido apoyo dado a las guerras de liberación nacional.

Las implicaciones de este apoyo han sido sumamente exageradas por el Occidente. Veamos, ¿qué es en realidad lo que los chinos dicen? Ellos opinan que la "guerra popular" siguiendo el molde maoísta es la única cstrategia efectiva en la lucha contra el colonianismo y neocolonialismo y critican a la Unión Soviética por destacar en exceso la posibiliclacl de una "transición pacífica" hacia el socialismo en tales situaciones. Ellos ‘cen que en el futuro el mundo subdesarrollado -el "campo mundial"- rodeari y triunfará sobre el mundo desarrollado - las "ciudades mundiales"- Esta teoría es una analogia de la guerra civil china: los comunistas utilizaron el apoyo popular entre el campesinado para aislar y erentualmente aniquilar el po- 
derio de fos nacionalistas, quienes en gtan parte eran de otigen y resilencia urbana. Pero los chinos también dieen -y esto es de stma importancia- que la revolución es un proceso nativa. Solamente pueste ser tealizasia por las habitantes del pais donde ocurre. Fsto no excluye el apoyo externo, pero en todo caso tal respaklo tendria una importancia sulo secundaria.

Esta cs Ia doctrina china sobre libcración nacional, expresada con toda claridad por cl mariscal Lin Piao durante su famoso discurso de septiembre de 1965 sobre la "guerra popular". Debe notarse que aquí nos encontramos cón doctrina, simple y pura doctrina. Es cstc articulo de fe, una prolecla del futuro de la cual implicitamente se crec. No nos da información alguna sobre lo que los chinos pueden o no eventualmente hacer en ạpoyo de situaciones revolucionarias especificas. No es, en absoluto, un plan de acción.

Dejemos ahora las palabras $y$ observemos los hechos. Encontramos un cuadro muy diferente. El apoyo chino a movimientos revolucionarios -aparte de la propaganda - en Asia ha sido en realidad altamente selectivo. China ha intercnido y asistido sustancialmente sólo a Corea del Norte, Vietnam del Norte y Laos-todos estos tres países limitrofes de China y donde a su vez Estados Unidos también ha intervenido-. Debemos además agregar el nombre de Tailandia a esta lista, donde la respuesta china al considerable aumento del contingente militar norteamericano dentro de ese país, se ha manifestado en su apoyo al recién nacido movimiento de liberación nacional. En el resto de Asia, China ha intentado intervenir solamente dentro de paises neutrales y libres de toda dominación extranjera. Aparentemente, en Asia por lo menos, China valoriza mucho más a sus vecinos neutrales que a la causa de la revolución.

La historia es algo diferente en el resto del mundo. Es cierto que China ha dado algún tipo de asistencia -armas o adiestramiento- a revolucionarios africanos y latinoamericanos. Esta ayuda jamás ha sido muy abundante y ha disminuido durante 1965-1966. Fue selectiva y no se distribuyó muy sabiamente. Muchas veces los que han recibido ayuda china har sido más bien oportunistas antes que maoistas. No es que queramos restarle importancia a esta asistencia, pero se da en forma demasiado desordenada y esporádica como para sugerir un gran plan chino de subversión mundial. Norteamérica desarrolla actividades similares en una escala muchisimo mayor.

Lo que realmente despierta nuestra atención son las palabras de China y no sus acciones. Cuando un Chou En-lai proclaraa a grandes voces que Africa estí "nadura para una revolución", lo que él está haciendo es profetizar algo que le parece obvio. Para el resto del mundo, es de tono amenazante. Aquí tenemos otro ejemplo donde el dogma chino triunfalmente brilla sobre la practicabilidad. Tácticamente, seria mucho más sabio que China bajase el tono de su propaganda revolucionaria. Sin embargo, muy al contrario, cada dia se hace más propaganda, haciendo caso omiso de los posibles efectos negativos. 


\section{Cinsa Y las armas NCCLEARES}

Otra interrogante que atemoriza y alarma a Occidente es que China haya emergido dentro de la escena nuclear. Habría que hacer antes que nada una obsernación general respecto a la política militar China. Desde 1949, la estrategia y planeamjento militar han sido orientados casi cxclusivamente hacia la delensa. Esto no excluje operaciones limitadas de tipo olensivo como la guerra limítrofe chino-hindú. Pero la preocupación central de la estrategia china es defender su territorio de la agresión externa, sea ésta proveniente. de los Estados Unidos o por último de la Unión Soviética. Si examinamos el tipo de armas y sistemas de combate que se han adoptado en el ejército, armada y fucrza aérea, esta misma preocupación primordial por la defensa nos será revelada.

Si China tuviese ambiciones expansionistas, se notarian tales planes en sus preparativos militares, tal como las intenciones de Alemania y Japón se podían adivinar en la década de 1930 si se observaba sus programas de rearmamento. Sin embargo, todos los expertos en la capacidad militar china concuerdan en que sus posibilidades para una acción ofensiva de gran envergadura fuera de sus fronteras' son casi inexistentes y que ningún esfuerzo importante se ha realizado para mejorarlas.

Por motivos obvios, es en el campo del desarrollo de armas nucleares donde se han efectuado grandes esfuerzos. El programa nuclear de China Iue acelerado en 1958, el año en que comenzó a adquirir importancia la disputa chino-sovićtica. China ya no podía contar con la garantía nuclear de la Unión Soviética; por lo tanto la posesión de un disuasivo nuclear propio era de vital importancia. China actualmente busca aunque sea un "disuasivo mínimo" con el cual evitar el posible ataque. Sucesos recientes parecen indicar que está bien encaminada hacia su obtención.

Los motivos chinos para unirse al grupo nuclear son por lo tanto iguales a los de los actuales miembros - la búsqueda de seguridad y también, podemos agregar, de prestigio. La posesión de armas nucleares no tornaria a la China ni más ni menos "agresiva" que cualquier otro poder nuclear.

¿Qué efecto tendrí esto sobre las posibilidades de llegar al control de armamentos $y$ desarme nuclear? Desgraciada pero muy comprensiblemente, no es probable que Chisa consienta en participar en pactos de tal naturaleza hasta que verdaderamente cuente con algo que negociar. O sea, con una respetable fuerza nuclear propia. El Occidente perdió una oportunidad en 1957-195s, cuando China estimaba que debia existir una "zona no-nuclear" en Asia y el Pacifico. Aunque por el momento se debe tratar de incluir a China dentro de este tipo de ncgociaciones, no se puede esperar que estas tengan exito a corto plazo. 


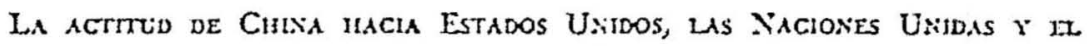
PROBLEMA DE TAIW:S

La actitud china hacia los problemas relacionados con Estados Unidos, las Naciones Unidas y Taiwán, permiten observar claramente su vuela hacia una politica exterior pasiva y a la espera. China aparentemente ha descartado toda posibilidad :e llegar a un acuerdo sobre tales materias antes de un futuro indefinido.

Uno de los poquísimos documentos secretos sobre política exterior china llegado a nuestras manos trata detalladamente sobre estos problemas, y da una explicación particularmente franca. Este documento, que seguramente se originó a nivel del Comité Central, fue redactado en 1961. Desde entonces no ha sucedido nada que lo invalide asi que podemos considerar sus conclusiones como el punto de vista de Chira.

Respecto a las Naciones Unidas, el documento explica que:

"Si nuestro país se incorpora a la xu, no podremos contar con una mayoría de votación; fomalmente se podría modificar tal difícil situación hasta cierto punto, pero en la realidad la lucha iniciada sería más violenta y perderiamos nuestra libertad de acción".

Más recientemente, los jefes chinos han pedido a las Naciones Unidas que se reforme a si misma, que revoque la resolución sobre la guerra en Corea que acusó y dejó marcada a China como a un agresor, que dé cabida a Vietman del Norte y. Corea del Norte, que elimine a varios miembros representantes de regímenes titeres, etc. Estas exigencias no deben considerarse con extrema seriedad y puede que no representen más que puntos máximos de transacción. Que la agenda del año 1966 de la Nu incluyese la resolución de admisión de China, indica que ésta aun mantiene un interés por esta entidad. Sin embargo, actualmente China no tiene en absoluto la misma ansiedad de hace algunos años por incorporarse a las Naciones Unidas.

EI problema de Taiwán es el obstáculo más importante que impide el mejoramiento de las relaciones entre Estados Unidos y China. China ha dejado de Jado sus intenciones de apoderarse de Taiwán por medio de la \{uerza. Aparentemente está dispuesta a esperar hasta que la ocupación militar en esa isla muera de muerte natural. En el intertanto, no está dispuesta a aceptar solución de arreglo alguno respecto a la situación legal de Taiwán, ya sea en la xu o por sí sola. El documento secreto citado anteriormente dice:

"China es un nucro pais socialista, y si cedc o permite que un cjército imperialista ocupe nuestro propio territorio, su prestigio internacional será destruido. Por el momento no necesitamos recuperar Taixán, obtenien. 


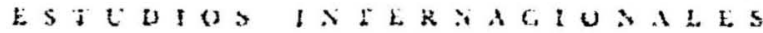

do asi que Estados Lnidos continue sn una situación ambigus, criticalos pero incapaces de reconocer el estado legal de la ocupación".

En cuanto a las relaciones con Estados Unidos, Chiria cree que algún día se logrará un acuerdo, pero decididamente no dentro de un plazo próximo. Ella insiste en que una solución total es la única respuesta a los principalcs problemas. Por esto rechaza gestos simbólicos tales como las facilidades que Norteamérica recientemente ha estado otorgando para la obtención de pasaportes a periodistas y estudiantes que visitan China. El mismo documento citado observa:

"Más vale mantener una relación estacionaria entre China y los Estados Unidos, yue la clesavenencia dure muchos años. Si este problema se ha de resolver, deseamos que esto se haga de una vez; o sea, el retiro de las tropas de Estados Únidos de Taiwán, reconocimiento de la nueva China, intercambio de periodistas, etc. Todo esto ha de ser resuelto en forma simultánea... Hasta el momento, no nos parece ver signo alguno de mayor ductilidad respecto a las relaciones chino-norteamericanas ni menos seña alguna de sinceridad".

Si se considera la guerra de Vietnam, el juicio actual de la China sería aún mucho más duro.

\section{LA DISPUTA CHINO-SOVIF́tTICA}

La disputa chino-soviética, como ya hemos expuesto, lejos de ser inesperada - refractaria, fue la consecuencia lógica de la relación poco equilibrada entre China y la Unión Soviética. Pero la forma que esta disputa ha adquirido en gran parte ha sido dictada por tácticas chinas. Recientemente esta táctica ha culminado en una situación decididamente desfavorable para China.

La agravación que ha experimentado esta disputa se puede comparar con el desarrollo de una guerra. Hasta 1962, las diferencias fueron ocultadas y mantenidas en privado, mostrando un frente de formal solidaridad en público. Después de la crisis de Cuba y de la guerra limítrofe chinothindú, la disputa se hizo abierta, aunque China se reprimió de abiertamente desafiar el liderato soviético del mundo comunista. En esta fase, China todavía gozaba con apoyo considerable por parte de otros miembros del bloque socialista, quienes - guiados por motivos propios- buscaban mayor independencia de la Unión Soviética. Entre estos países se contal un: Rumaria, PoIonia; Cuba, Vietnam del Norte y Corea del Norte. En 1964, ya la China abiertamente disputaba con la Unión Soviética el liderato del bloque. Esta era aun una politica viable, siempre que China evitase la posibilidad de an- 


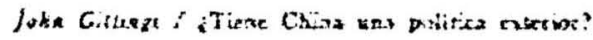

tagonizar a otros paixes socialistas. Pero China ha llowado recientemente esta disputa a ales extremos que hain sus propios simpatizantes sa han sentido descucantados. Las actividades facuionarias de China, su politica restrecto al Vietnam, el tono prepotente de sus polimicas y sus velaclos atufucs al resto de los paises socialistas - sin mencionar ia Revolución Cultural- han logrado apartarla de casi li totalidad de sus aliados excepto Albania.

Debemos destacar que la Unión Sovietica una vez más. ha tratado de cfec. tuar una reunión inte:nacional de partidos conunistas; reunión para la cual anteriormente Khrushchey habia encontraclo sólo oposición. Corca cel Norte y Vietnam del Nortc, antiguos aliados de China, hace.poco se han tornado casi neutrales dentro de la disputa. Las relaciones con Cuba se deierioraron durante el transcurso del año 1966 y una cantidad de partidos comunistas extranjeros - notoriamente el Particlo Comunista del Japón- han dejado de apoyar China.

Aquí, a grandes trazos, podemos leer y captar la doctrina milenarista de Mac. Puede ser que China haya minado el liderato soviético, pero sus tácticas a la vez han destruido su propio apoyo. China es intransigente respecto al apoyo que reciba. Descle su punto de vista, la doctrina reviste muchísimo más importancia que la conveniencia. ¿Qué importancia tiene si acaso la gran mayoría - "mayoría mecánica" como China despreciativamente la calificaestá contra uno? La minoria es la que custodia la verdad y son ellos los que prevalecerín.

\section{VIETNAMT}

Todos estos hechos nos llevan inevitablemente a tratar el tema de la guerra en Vietnam, porque ha sido la actitud de China hacia este conflicto lo que mayor número de adeptos la ha hecho perder durante el transcurso del año pasado. Debemos establecer claramente que ésta no es ni jamás ha sido una guerra china. Es esencialmente una guerri civil cuyas raíces politicas, sociales y económicas pueden atribuirse directamente a la situación en Vietnam deI Sur bajo la dictadura Diem y la junta militar que sucedió a ésta. La decisión tomada por Vietnam del Norte é 1960 en cuanto a dar su respaldo. a la guerra civil del sur, fue una decisión de Hanoi y en momento alguno de Pekin. Existe una facción prochina en Hanoi, pero no existe evidencia alguna de que esta facción por si sola decida la politica a seguir. La jefatura norvietnamita aparentemente está unida en su decisión de apoyar a sus compatriotas del sur.

Si revisamos la actitud de China hacia la guerra de Vietnam, desde los comicnzos del 'escalamiento americano en febrero de 1965 hasta la Revolución Cultural, podremos reconocer varios cambios de gran significación. Aunque cada uno de estos giros por si mismo aparentemente revista poca 


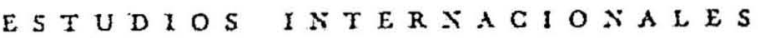

importancia, obserrados en conjunto dan un resultado que sólo puede in. dicar un cambio de politica deliberado.

En primer lugar, las promesas de China de apoyar al Victnam son cada vez más débiles y menos incondicionales. En 1965, China declaró frecuentemente que daria toda la ajuda requerida por el pucblo vietnamés y que esta a)uda incluiria tropas si tal petición fuese hecha. Durante la Revolución Cultural, el volumen de declaraciones chinas respecto al Vietnam disminuyó notablemente. Además, sus promesas de ayuda comenzaron a ser emitidas en lenguaje mucho más cauteloso, y' tcrminaron todas las menciones respecto al envío de tropas.

Aunque las probabilidades de una acción chino-soviética conjunta en el caso del Vietnam nunca fueron muy poderosas, China en un comienzo no las eliminó del todo. También se abstuvo de polemizar en forma excesiva en contra de la Unión Soviética. Con el transcurrir del tiempo, sin embargo, China categóricamente rechazó toda posibilidad de "acción conjunta" con la Unión Soviética y agravó el tono de sus polémicas, acusando repentinamente a la Unión Soviética de colaborar con los Estados Unidos para traicionar a los vietnamitas. Esto fue lo que causó la separación entre China y Corea del Norte y el Partido Comunista de Japón, ya que ambos aparentemente piensan que una crisis de la magnitud de la del Vietnam exige la colaboración, aunque sea de una naturaleza limitada y para "revisionistas modernos".

La política militar china tambièn ha sufrido un giro en su dirección. Cuando comenzó el 'escalamiento' de Norteamérica, las declaraciones chinas destacaron el peligro de una segunda "Corea", implicitamente insinuando que tal vez se viese obligada a intervenir. Otras declaraciones mencionaban la nécesidad de electuar "mil $g$ ' uno" preparativos militares y también insinuaban la posibilidad de algún tipo de acción de prioridad. Mas recientemente, el reclutamiento político a largo plazo - que significa una campaña intensiva de educación política dentro del ejército de China- ha sido más destacado a expensas del reclutamiento militar y el apremio de la crisis ha sido bastante ignorado. Aunque no se puede decir con seguridad si China intervendrá ó no en el Vietnam, declaraciones chinas aparentemente afirman que no está dispuesta a recurrir a tal acción salvo que su propio territorio sea invadido.

Finalmente, la interpretación china del significado de la guerra también ha experimentado un cambio. En un principio se la consideraba únicamente dentro de su contexto vicumamita, como un claro y preciso caso del apoyo dado por el imperialismo norteamericano a un gobierno titere neocolonialista, por añadidura contrario al pueblo de Viecnam. Desde fines de 1965, sin embargo, cada rez mis a menudo se describe esta guerra como simplemente un elemento - una cabeza de lanza- dentro de los declarados planes norteamericanos de rodear su territorio o incluso llegar a una gruerra con 
China misma. Por lo tanto la dirección chino-céntrica se ha alejaclo de la situación actual y se ha dedicado directamente a estudiar la posibilidad fu. tura de una invasión de Estados Úniclos.

Aparentemente, durante 1965 la guerra en Victnam ofreció a China varias alternativas en cuanto a la politica a seguir. Una era la de colocar al pais en pic de guerra y prepararse para intervenir en Vietnam. Otra, no necesariamente incompatil'’ con la primera, era la de unirse a la Unión Soviética para plancar alguna forma de acción conjunta. Ambas alternativas cran consideradas por los licleres maoístas respectivamente como "aventurerismo de izquierda" y "oportunismo de derecha". Tal vez la caida en desgracia de algunas importantes personalidades durante la Revolución Cultural pueda ser atribuido a este debate. Llegado el momento se optó por un camino intermedio entre estas dos alternativas.

Este camino es el de postergar una preocupación inmediata por la situación en Vietnam y concentrarse en un reclutamiento ideológico y político del pueblo chino en anticipación a una posible guerra con los Estados Unidos. Aunque China continúe regalando cantidades considerables de armamentos al Vietnam, esa guerra es esencialmente un problema vietnamita. El eventual triunfo o derrota depende principalmente de los esfuerzos del pueblo de Vietnam y algunas declaraciones chinas parceen sugerir que aún les quedan muchos reveses que sobrellevar antes de conseguir la victoria. En el intertanto, los chinos, de un modo casi fatalista, observan lo que sucede. Confiados en la doctrina de la guerra popular, y en la movilización ideológica provocada por la Revolución Cultural, están preparados para lo peor. En realidad, es la Revolución Cultural y no Vietnam la que ahora ocupa el lugar central dentro de sus preocupaciones.

\section{La Revolución Culjural}

Las causas de la Revolución Cultural son muchas y muy complejas. En su esencia es la culminación de la búsqueda de "sucesores revolucionarios" a la actual jefatura y para eliminar los gérmenes de revisionismo doméstico que comenzaron con el "movimiento de educación socialista" de 1963. También están implicados elementos que desatadamente luchan por el poder. Pero existe un sentido en que este movimiento está directamente unido a la politica exterior. La Revolución Cultural coincide con un periodo en que la política externa de China ha sufrido sólo reveses o encontrado fines estériles. La Revolución Cultural representa una vuelta desde el mundo externo y a la vez una pérdida de interés en este, incluyendo la guerra en Victnam. No scría exagerado adivinar el estilo de Ma tras todo esto. El Gran Salto Adelante fue un intento de revolucionar la politica económica de China y falló -aunque esta falla haya sido causada parcialmente por motivos fuem de control chino. El rompimiento chino-soviético, y sus consecuentes nuevas alineaciones, fueron 


\section{ESTLDIOS IXIERNACIOXALES}

un intento para revolucionar la politica exterinr china. También fallo este intento y nuevamente por motivos que en su mayoria cscapaban al control chino. Frustrados en su politica econónica y caterna, Mao y sus compañeros dedican ahora stu acención a lo que consideran la clave de sus problemas. E1 adoctrinamiento revolucionario comicnza en lo propio: la Revolución Cultural es un intento de indoctrinacjón global de la sociedad china.

Las frustraciones sufriclas por China en el campo de los asuntos internacionales durante los años recientenente transcurridos, se combinan con los caracteres centripetos $c$ introspectivos de la experiencia histórica china para producir una situación curiosa que nos permite en forma casi absoluta opinar lo siguiente: China es un pais que no cuenta con una politica exterior explícita y digna de mención. 